\title{
Competentiegericht astma-onderwijs aan huisartsen- in-opleiding: door onderwijs ondersteunde kwaliteits- zorg en de effecten op de klinische toestand van de begeleide patiënten
}

\author{
B.J. van Duin, A.E. Hesselink
}

\section{Samenvatting}

Inleiding: Om de competenties van huisartsen-in-opleiding (HAIO's) bij astma te ontwikkelen, is bij het Vrije Universiteit Medisch Centrum (VUmc) een keuzemodule uitgevoerd, waarbij HAIO's slecht ingestelde astmapatiënten in de stage-huisartspraktijk begeleidden. De consulten werden gefaciliteerd door onderwijsbijeenkomsten, die wat betreft inhoud en planning in de tijd afgestemd waren op de consulten in de praktijk.

Methode: De 16 deelnemende HAIO's namen 72 patiënten in zorg, waarvan er 38 het begeleidingstraject ook afmaakten. De consulten vonden conform huisartsgeneeskundige richtlijnen plaats aan de hand van een werkboek, waarin ook de bevindingen tijdens de patiëntcontacten werden vastgelegd.

Resultaten: De keuzemodule was goed uitvoerbaar. Er waren geen duidelijke verschillen wat betreft geslacht, leeftijd en diagnose tussen de patiënten die het begeleidingstraject wél, respectievelijk niet afmaakten. Vergelijking van het eerste en het laatste consult laat zien dat er bij de patiënten die de begeleiding afmaakten, zowel wat betreft klachten als wat betreft longfunctieparameters significante verbetering was opgetreden.

Discussie en conclusies: Praktijkgericht onderwijs bij een chronische aandoening, waarbij HAIO's gericht en systematisch de richtlijnen hiervoor leren toepassen, lijkt samen te kunnen gaan met het verbeteren van de kwaliteit van zorg. Ook voor andere opleidingen in de gezondheidszorg, waarin leren en werken gecombineerd worden, liggen er wellicht mogelijkheden om onderwijs en verbetering van zorg met elkaar te verbinden. (Duin BJ van, Hesselink AE. Competentiegericht astma-onderwijs aan huisartsen in opleiding: door onderwijs ondersteunde kwaliteitszorg en de effecten op de klinische toestand van de begeleide patiënten. Tijdschrift voor Medisch Onderwijs 2004;23(6):281-290.)

\section{Inleiding}

De zorg bij chronische aandoeningen is een centraal thema in het derde jaar van de driejarige huisartsopleiding van het Vrije Universiteit Medisch Centrum (VUmc) Amsterdam. In de praktijk blijken patiënten met chronische aandoeningen echter vaker bij de eigen huisarts dan bij de huisarts-in-opleiding (HAIO) te komen. ${ }^{1}$ Het kennisniveau van HAIO's ten aanzien van chronische ziekten aan het einde van de beroepsopleiding is dan ook relatief laag. ${ }^{2}$
Om zich binnen een beroepsopleiding de competenties voor het omgaan met patiënten met een chronische aandoening te verwerven, is het essentieel dat hier voldoende praktijkervaring mee wordt opgedaan. Daarnaast is het van belang dat het beroepshandelen centraal staat in het onderwijs. ${ }^{3-7} \mathrm{Bij}$ de huisartsopleiding van het VUmc is daarom de keuzemodule 'Begeleiden bij instabiel astma' voor derdejaars HAIO's ontwikkeld. Deze module is gericht op astmapatiënten en gebaseerd op de NHG-standaarden over astma. ${ }^{8} 11$ 
Er is voor de aandoening astma gekozen, omdat het een veel voorkomende aandoening is, waarbij verbetering van de zorg goed mogelijk is. In de Nederlandse huisartspraktijk is de prevalentie ongeveer 13 per $1000 .{ }^{8}$ Hoewel de behandelingsmogelijkheden de laatste decennia sterk verbeterd zijn, heeft gemiddeld een derde tot de helft van de bij de huisarts bekende astmapatiënten klachten en beperkingen door astma. ${ }^{9-10}$ Onderbehandeling, fouten in de inhalatietechniek en een slechte therapietrouw zijn hierbij belangrijke factoren. ${ }^{11-12}$

In dit artikel beschrijven we de keuzemodule voor HAIO's, die gericht is op een systematische begeleiding van slecht ingestelde astmapatiënten door HAIO's en het effect daarvan op de praktijk. We laten de opbouw en de elementen van de keuzemodule zien en presenteren enige gegevens over de uitvoering van de consulten. Om te kijken of de module effect heeft in de praktijk worden de klachten en de longfunctie bij het eerste en het laatste consult van de begeleide astmapatiënten vergeleken.

\section{Methode}

\section{Setting}

De HAIO's waren werkzaam in huisartspraktijken in de regio Noord Holland, waar zij hun derdejaars-stage liepen. In totaal namen 16 huisartspraktijken deel. De HAIO's maakten bij de begeleiding gebruik van een werkboek, bestaande uit een instructiedeel met daarin een toelichting op de uit te voeren activiteiten en een registratiedeel, waarin de resultaten van al deze activiteiten werden vastgelegd. Daarnaast werd de uitvoering van de consulten ondersteund door onderwijsbijeenkomsten. Deze opzet maakte de module competentiegericht: het daadwerkelijk gaan werken met astmapatiënten in de opleidingspraktijk staat centraal en de rol van het instituutsonderwijs is daarbij ondersteunend en faciliterend. De vorm van de module paste daardoor goed bij de uitgangspunten van het nieuwe raamplan voor de huisartsopleiding. ${ }^{4}$

\section{Deelname HAIO's}

Vier achtereenvolgende derdejaars HAIOgroepen (gemiddeld 12 HAIO's per groep) volgden aan het begin van hun derde jaar één dagdeel regulier onderwijs over astma en chronisch obstructieve longaandoeningen (COPD), zoals emfyseem en bronchitis. Aan het einde van dit dagdeel konden de HAIO's kiezen voor deelname aan de keuzemodule 'Begeleiden bij instabiel astma'.

De HAIO's die voor de keuzemodule kozen, kregen een werkboek dat bestond uit een instructiedeel en een registratiedeel. Het instructiedeel was gebaseerd op de NHG-standaarden over astma. ${ }^{8} 11$ In het registratiedeel was onder andere ruimte voor de antwoorden op anamnesevragen, de resultaten van eenvoudig lichamelijk onderzoek en spirometrie, gegevens over gemaakte fouten bij het inhaleren en de therapietrouw en (veranderingen in) de behandelplannen. Ook ontvingen de HAIO's een gekalibreerde spirometer in bruikleen voor de duur van de module.

\section{Inhoud onderwijsbijeenkomsten en praktijkactiviteiten}

Tijdens de keuzemodule begeleidden de HAIO's, ondersteund en begeleid vanuit de huisartsopleiding, patiënten met slecht ingesteld astma. Het gehele begeleidingstraject van de astmapatiënten nam gemiddeld 3-4 maanden in beslag, waarbij tussen het eerste en het tweede consult 2 weken tijd zat en tussen de daaropvolgende controleafspraken 4-6 weken. De uitvoering van de consulten werd onder- 
steund door onderwijsbijeenkomsten die aangeboden werden op het onderwijsinstituut. De planning en de inhoud van de onderwijsbijeenkomsten was afgestemd op het begeleidingstraject in de praktijk. Tijdens alle bijeenkomsten werd aandacht besteed aan het komende consult, waarbij de daarvoor benodigde kennis en vaardigheden werden besproken en geoefend. Daarnaast werden ook de praktijkervaringen van het afgelopen consult besproken. Als aanvullende methodes werden hierbij intercollegiale consultatie en consultatie door een inhoudsdeskundig docent gebruikt. Dit werd aangevuld met het oefenen van specifieke vaardigheden (zie tabel 1).

\section{Selectie patiënten}

De selectie van slecht ingestelde astmapatiënten door de HAIO's vond volgens de instructie in het werkboek stapsgewijs plaats: als eerste stap werden op medicatiecode de patiënten geselecteerd die alléén kortwerkende betamimetica gebruikten (3 of meer prescripties in het laatste jaar) en daarná de patiënten die daarbij ook wel eens inhalatiesteroïden voorgeschreven hadden gekregen (maximaal één prescriptie in het laatste jaar).

Als tweede stap werd bij deze patiënten, als ze tussen de 18 en 65 jaar oud waren, in de journaalgegevens gekeken of er het laatste jaar minimaal één contact vanwege luchtwegklachten geweest was. Patiënten die hieraan voldeden en geen andere longziekten hadden, werden uitgenodigd om een afspraak te maken. In de door de eigen huisarts ondertekende uitnodigingsbrief werd uitgelegd dat hun luchtwegklachten nader onderzocht zouden worden, om te bekijken of er verbetering van hun klachten mogelijk was.

$\mathrm{Na}$ afloop van het eerste consult stelde de HAIO op grond van de criteria van de NHG-standaarden 8 een werkdiagnose.
Alleen patiënten die voldeden aan de criteria voor 'astma' of 'astma met persisterende luchtwegobstructie' kregen structurele begeleiding aangeboden.

\section{Metingen en analyse}

Aan de hand van de ingevulde registraties van de consulten werd per HAIO gekeken welke consulten daadwerkelijk uitgevoerd werden. Tijdens de onderwijsbijeenkomsten werd aandacht besteed aan redenen voor het niet uitvoeren van (onderdelen van) de consulten.

Bij de analyses werden de gegevens van patiënten die tenminste consulten 1, 2 en 5 hadden ontvangen, meegenomen. Hierbij waren de volgende gepaarde metingen uit consult 1 en 5 van belang:

- Het al dan niet aanwezig zijn van afwijkende longgeluiden (verlengd expirium, rhonchi, crepitaties).

- Het al dan niet aanwezig zijn van specifieke luchtwegklachten gedurende de laatste 3 maanden en de vraag of deze de meeste dagen/nachten aanwezig waren.

- Het al dan niet 's nachts wakker worden van luchtwegklachten.

- De één-seconde waarde (FEV-1) bij longfunctieonderzoek als percentage van de voorspelde waarde, zowel vóór als na toediening van een luchtwegverwijder.

Deze gegevens werden met elkaar vergeleken om zicht te krijgen op de veranderingen in klachten en longfunctieparameters bij de begeleide patiënten.

De resultaten werden geanalyseerd met behulp van het statistiekprogramma SPSS 8.0. Verschillen in het al dan niet aanwezig zijn van afwijkingen bij het beluisteren van de longen of van luchtwegklachten werden getoetst met de methode van Wilcoxon. Voor het vergelijken van de longfunctieparameters werd gebruik gemaakt van de t-toets. 
Tabel 1. Afstemming in de tijd en de globale inhoud van consulten en onderwijs.

\begin{tabular}{lll}
\hline & $\begin{array}{l}\text { Inhoud en duur onderwijs } \\
\text { huisartsopleiding }\end{array}$ & Opleidingspraktijk \\
\hline Onderwijsbijeenkomst $\mathbf{0}$ & $\begin{array}{l}\text { Instructie voor selecteren patiënten, } \\
\text { vaardigheidstrainingen 'Uitvoeren } \\
\text { spirometrie' en 'Bespreken eigen } \\
\text { ideeën patiënt over klachten en } \\
\text { medicatie' (3 uur). }\end{array}$ & \\
\hline Onderwijsbijeenkomst 1 1 & $\begin{array}{l}\text { Bespreken ervaringen met selecteren } \\
\text { en oproepen patiënten, instructie } \\
\text { consult 1, vaardigheidstrainingen } \\
\text { 'Interpreteren spirometrie en } \\
\text { anamnese' en 'Bespreken } \\
\text { behandelingsplan' (3 uur). }\end{array}$ & \\
\hline Consult 1 & & $\begin{array}{l}\text { Diagnostisch consult volgens richt- } \\
\text { lijnen NHG-standaarden (incl. spiro- } \\
\text { metrie en reversibiliteit), vaststellen } \\
\text { behandelplan. }\end{array}$ \\
& &
\end{tabular}

Onderwijsbijeenkomst 2 Bespreken ervaringen consult 1, instructie consult 2, vaardigheidstrainingen 'Herkennen van essentiële fouten bij inhaleren' en 'Bespreken van therapietrouw' (3 uur).

\section{Consult 2}

Bespreken beloop klachten, evt. bijstellen medicatie, checken en waar nodig corrigeren inhalatietechniek, bespreken en actief bevorderen therapietrouw.

Onderwijsbijeenkomst 3 Bespreken ervaringen consult 2, instructie consult 3 , vaardigheidstrainingen 'Bespreken uitlokkende prikkels' en 'Omgaan met steroïdenangst' (3 uur).

\section{Consult 3}

Als consult 2 én (wanneer van toepassing) bespreken verminderen blootstelling aan huisstof en belang van stoppen met roken.

\begin{tabular}{ll}
\hline Consult 4 (facultatief) & Bij voortduren klachten of meer \\
& behoefte aan instructie/begeleiding \\
& bij patiënt.
\end{tabular}

Onderwijsbijeenkomst 4 Bespreken ervaringen consult 3 en 4, instructie consult 5 , vaardigheidstraining 'Bespreken afbouwschema medicatie' en 'Follow-up beleid' (3 uur). 


\section{Inhoud en duur onderwijs Opleidingspraktijk \\ huisartsopleiding}

$\begin{array}{ll}\text { Consult } 5 & \text { In kaart brengen klachten, omgaan } \\ \text { met astma en spirometrie conform } \\ \text { consult 1. Aan de hand van resul- } \\ \text { taten vaststellen en bespreken } \\ \text { follow-up beleid wat betreft } \\ \text { medicatiegebruik en controles. } \\ \text { Nabespreking met HAIO. }\end{array}$

Onderwijsbijeenkomst 5 Bespreken ervaringen consult 5, evalueren module (3 uur).

\section{Resultaten}

Zestien derdejaars HAIO's namen deel aan de keuzemodule 'Begeleiden bij instabiel astma'. In totaal namen deze HAIO's 72 patiënten in zorg. Van deze 72 patiënten voldeden er achteraf bezien 3 niet aan de criteria voor een werkdiagnose 'astma' of 'astma met persisterende luchtwegobstructie'. Zij bleken COPD te hebben. In totaal doorliepen 38 patiënten het gehele begeleidingstraject, waaronder 2 van de 3 COPD-patiënten.

Het aantal ingesloten patiënten per HAIO varieerde tussen de 1 en de 9 (gemiddeld 4,5). Ook waren er grote verschillen tussen de HAIO's onderling in het aantal consulten per patiënt. Drie HAIO's voerden alle consulten bij alle ingesloten patiënten uit. Bij de andere HAIO's was er een per HAIO wisselende mate van uitval gedurende het begeleidingstraject.

Alle HAIO's volgden alle geplande onderwijsbijeenkomsten (een enkele maal individueel ingehaald bij afwezigheid tijdens de groepsbijeenkomst).

Het bleek goed mogelijk de consulten in de praktijken en de onderwijsbijeenkomsten op elkaar af te stemmen. De vaardigheidstrainingen sloten goed aan bij de praktijk en er was voldoende tijd voor consultatie over in de praktijk ervaren problemen.
Er waren geen duidelijke verschillen wat betreft geslacht, leeftijd en werkdiagnose tussen de patiëntgroepen die het begeleidingstraject wèl, respectievelijk níet afmaakten (zie tabel 2).

Tabel 3 beschrijft de resultaten van de metingen bij patiënten in de consulten 1 en 5 . Bij vergelijking van de twee consulten bleek er voor alle gebruikte parameters een statistisch significante verbetering te zijn opgetreden. Niet alleen de klachten van de patiënten en de bevindingen bij auscultatie van de longen, maar ook de longfunctieparameters (éénseconde waarde en reversibiliteit) bleken sterk verbeterd te zijn.

\section{Discussie en conclusies}

\section{De uitvoering van de module}

De keuzemodule 'Begeleiden bij instabiel astma' was facultatief. $33 \%$ van de derdejaars HAIO's aan wie de module aangeboden werd, maakte gebruik van dit aanbod en participeerde in de module. Alle deelnemende HAIO's voerden minimaal één keer alle stappen van het begeleidingstraject uit. Het bleek goed mogelijk de consulten in de praktijken en de onderwijsbijeenkomsten in de tijd op elkaar af te stemmen. 
Tabel 2. Kenmerken van patiënten die het begeleidingstraject wel of niet afmaakten.

\begin{tabular}{|c|c|c|}
\hline & Wel afgemaakt $(\mathrm{N}=38)$ & Niet afgemaakt $(\mathrm{N}=34)$ \\
\hline Geslacht & $M=16(42,1 \%) ; V=22(57,9 \%)$ & $M=13(38,2 \%) ; V=21(61,8 \%)$ \\
\hline Gemiddelde leeftijd & 39,4 jaar & 40,7 jaar \\
\hline \multicolumn{3}{|c|}{ Werkdiagnose na consult 1:* } \\
\hline Astma & $70,3 \%$ & $84,4 \%$ \\
\hline \multicolumn{3}{|c|}{ 'Astma met persisterende } \\
\hline luchtwegobstructie' & $24,3 \%$ & $12,5 \%$ \\
\hline COPD & $5,4 \%$ & $3,1 \%$ \\
\hline
\end{tabular}

Tabel 3. Resultaten van het afgemaakt begeleidingstraject op klachten en longfunctie.

\begin{tabular}{lccc}
\hline & Consult 1 & Consult 5 & $\begin{array}{c}\text { P-waarde } \\
\text { verschil }\end{array}$ \\
\hline Afwijkingen hoorbaar bij auscultatie & & & \\
Hoesten laatste 3 maanden & $52,8 \%$ & $12,1 \%$ & 0,001 \\
Meeste dagen/nachten laatste 3 maanden hoesten & $76,3 \%$ & $23,7 \%$ & 0,002 \\
Piepen op de borst laatste 3 maanden & $60,5 \%$ & $21,1 \%$ & 0,000 \\
Meeste dagen/nachten laatste 3 maanden piepen op & $76,3 \%$ & $34,2 \%$ & 0,000 \\
de borst & $44,7 \%$ & $15,8 \%$ & 0,002 \\
Kortademigheid laatste 3 maanden & $89,5 \%$ & $55,3 \%$ & 0,002 \\
's Nachts wakker worden van kortademigheid & $63,2 \%$ & $26,3 \%$ & 0,002 \\
FEV-1 vóór luchtwegverwijder in \% t.o.v. van pred. & $78,08 \%$ & $85,69 \%$ & 0,003 \\
Mate van reversibiliteit op luchtwegverwijder in \% & & & \\
t.o.v. van pred. & $11,92 \%$ & $6,80 \%$ & 0,004 \\
\hline
\end{tabular}

Voor de meeste HAIO's was het de eerste keer dat ze de verantwoordelijkheid droegen voor een kwaliteitsproject in de huisartspraktijk. Er bleken dan ook grote verschillen te zijn tussen de HAIO's ten aanzien van het aantal patiënten dat terugkwam voor vervolgconsulten. Slechts enkele HAIO's slaagden er in elke patiënt het begeleidingstraject te laten doorlopen. Zowel de organisatorische en communicatieve vaardigheden van de HAIO als factoren in de opleidingspraktijk (spreekuurorganisatie, rol van de opleider en doktersassistente et cetera) leken hierbij een rol te spelen. HAIO's, die er in rollen- spellen tijdens de onderwijsbijeenkomsten blijk van gaven te beschikken over op de patiënt afgestemde advies- en voorlichtingsvaardigheden, leken ook meer succesvol te zijn in het terug laten komen van patiënten voor vervolgconsulten.

De directe afstemming tussen het werken met patiënten en het ondersteunend onderwijs had als resultaat dat de HAIO's zich goed voorbereid voelden op wat ze met de patiënten gingen doen. Daarnaast konden ervaren problemen in de uitvoering van de consulten besproken worden terwijl ze nog actueel waren. Doordat de HAIO's steeds met dezelfde fase van het 
begeleidingstraject bezig waren, werd duidelijk dat veel van de ingebrachte problemen door meerdere HAIO's ervaren werden. Hierdoor hadden werkvormen als intercollegiale consultatie en het (op elkaar) oefenen van gespreksvaardigheden een goed rendement.

De meeste HAIO's gaven aan dat ze zich na het uitvoeren van slechts enkele, volledige begeleidingstrajecten competent voelden in het uitvoeren van adequate diagnostiek en behandeling bij astma en dat ze na de module de ondersteuning van het werkboek niet meer nodig hadden.

\section{De resultaten op patiëntniveau}

Het feit dat er geen grote verschillen in patiëntkenmerken waren tussen de groep die het traject afmaakte en de groep die voortijdig afhaakte, geeft aan dat er geen sprake is van selectieve uitval. Van de 72 patiënten bleken er achteraf bezien 3 COPD te hebben en dus niet te voldoen aan de criteria voor een werkdiagnose 'astma' of 'astma met persisterende luchtwegobstructie'. Van deze 3 maakten 2 patiënten het begeleidingstraject ook af.

Bij de patiënten die tot het einde van het traject bleven komen, waren er duidelijke verbeteringen te zien: minder klachten, minder afwijkingen bij het beluisteren van de longgeluiden en een verbetering van de longfunctieparameters. Al deze verschillen zijn statistisch significant. Ofschoon dit een positief effect van de onderwijsmodule suggereert, dienen toch enkele kanttekeningen geplaatst te worden. Door het ontbreken van een controlegroep zijn de resultaten niet met zekerheid aan de interventie toe te schrijven. Bovendien is een deel van de uitkomstmaten subjectief en vastgelegd door de behandelende HAIO zelf. Ook is de uitval van patiënten groot, slechts iets meer dan de helft van de patiënten volgde het hele traject.
De gevonden verschillen in dit onderzoek zijn groter dan die in andere onderzoeken, waarin door onderwijs en/of nascholing geprobeerd werd de zorg aan astmapatiënten te verbeteren. ${ }^{13-16}$ Hiervoor zijn diverse verklaringen te geven:

De selectie van patiënten: patiënten die aan onze studie deelnamen, waren slecht ingestelde astmapatiënten met klachten, die gemotiveerd waren om zich tijdelijk te laten begeleiden.

De motivatie van de behandelend artsen: geïnteresseerde HAIO's, die zich op vrijwillige basis hadden aangemeld voor de keuzemodule en daarbij getraind en begeleid werden, namen deel aan dit onderzoek.

De nadruk lag in de consulten sterk op belangrijke lacunes in de zorg bij astma: inadequate medicamenteuze behandeling, het tekort schieten van de inhalatietechniek en onvoldoende therapietrouw.

Tenslotte was ook de beschikbare spreekuurtijd per patiënt duidelijk langer dan die van een gemiddelde huisarts.

De kosteneffectiviteit is niet expliciet in beeld gebracht. Deze lijkt bij dit project echter gunstig te zijn, omdat de HAIO's het uitvoerend werk in het kader van hun opleiding deden. Tevens was het project gericht op patiënten bij wie veel gezondheidswinst te behalen viel. Wanneer een huisarts zelf deze aanpak structureel bij alle astmapatiënten in de praktijk zou toepassen, ligt de verhouding tussen de tijdsinvestering van de huisarts en de opbrengst op patiëntniveau waarschijnlijk ongunstiger. Veel van de taken die uitgevoerd werden door HAIO's, zoals het uitvoeren van longfunctieonderzoek (spirometrie), het geven van instructie in het gebruik van inhalatiemedicatie en het corrigeren van gemaakte fouten hierbij en het (herhaaldelijk) bespreken van de therapietrouw zijn echter goed te delegeren aan een praktijkondersteuner (een 
verpleegkundige in dienst van een huisartspraktijk). Hierdoor kan de kwaliteit van zorg bij astma in de praktijk verbeterd worden zonder dat dit de huisarts zelf veel extra tijd kost.

\section{Kwaliteitsprojecten binnen beroeps- opleidingen}

Door zelf een kwaliteitsproject, gericht op een patiëntengroep met een chronische aandoening, in de opleidingspraktijk uit te voeren, leren HAIO's gericht en systematisch huisartsgeneeskundige richtlijnen toe te passen en competent te worden in de diagnostiek en behandeling van de betreffende patiëntengroep. Aan het einde van dit project vertelden veel HAIO's spontaan dat ze de tijdens deze module opgedane kennis nu ook in de gewone spreekuurcontacten bij (mogelijke) astmapatiënten toepasten. Mogelijk zal er ook 'transfer' optreden van de tijdens dit project verworven organisatorische en communicatieve vaardigheden naar toekomstige kwaliteitsprojecten gericht op andere patiëntgroepen.

Groepsonderwijs aan HAIO's die met een zelfde soort kwaliteitsproject op de stageplek bezig zijn, biedt onderwijskundig bezien belangrijke voordelen. HAIO's kunnen hierbij leren van elkaars praktijkervaringen: ervaren problemen kunnen ingebracht worden (ter consultatie) en in de vorm van rollenspelłen uitgespeeld worden. Ook is het goed mogelijk om het onderwijsaanbod af te stemmen op door de HAIO's in de praktijk ervaren lacunes in kennis en vaardigheden. HAIO's kunnen daarbij, mits gesuperviseerd door een inhoudsdeskundig docent, een rol vervullen bij het voorbereiden en uitvoeren van op deze lacunes gericht vervolgonderwijs.

De komende jaren wordt het nieuwe 'Raamplan huisartsopleiding' ${ }^{4}$ ingevoerd. De nadruk komt daarbij meer te liggen op het leren van patiëntcontacten op de stageplek. De belangrijkste functie van het onderwijs aan de huisartsopleidingen wordt het ondersteunen en faciliteren van dit leren in de praktijk.

Competentiegerichte beroepsopleidingen stellen bij hun onderwijs het beroepshandelen centraal. Bereikte competenties kunnen ingeschat worden aan de hand van registraties en observaties van relevante werkzaamheden en leeractiviteiten, maar ook door het beoordelen van resultaten op het niveau van de doelgroepen van het beroep.

Wanneer de huisartsopleiding ook de huisartsopleiders betrekt bij de keuze van de doelgroepen voor kwaliteitsprojecten en de ondersteuning van HAIO's bij de uitvoering ervan, dan lijken er nog betere mogelijkheden te zijn om het bereiken van de onderwijsdoelen van de HAIO samen te laten gaan met het verbeteren van de kwaliteit van zorg in de opleidingspraktijk. Ook binnen andere beroepsopleidingen waarin gewerkt wordt met de combinatie leren/werken, zoals de opleidingen voor medisch specialisten en die voor verpleegkundigen, kunnen patiëntgerichte kwaliteitsprojecten een effectieve manier van leren zijn met meerwaarde voor de erbij betrokken patiënten.

\section{Dankbetuiging}

Veel dank aan Henriëtte van der Horst voor haar heldere en deskundige adviezen en aan de HAIO's, die met enthousiasme meegedaan hebben aan het keuzeonderwijs. Ook dank aan de firma's Glaxo Smith Kline en Boehringer Ingelheim voor het ter beschikking stellen van de gebruikte spirometers.

\section{Literatuur}

1. Vintges $\mathrm{M}$, Weert $\mathrm{HC}$ van, Wiele E van de, Mohrs J, Brouwer HJ, Wigersma L. Welke gezondheidsproblemen zien huisartsen in opleiding? Huisarts Wet 2001;44:485-9. 
2. Leeuwen YD van, Mol SS, Pollemans MC, Drop MJ, Grol R, Vleuten CPM van der. Change in knowledge of general practitioners during their professional careers. Fam Pract 1995;12:313-7.

3. Rethans JJ, Norcini JJ, et al. The relationship between competence and performance: implications for assessing practice performance. Med Educ 2002;36(10):901-9.

4. Berkestijn LGM van, Bottema BJAM, Leeuwen Y van, Pieters R, Schoonheim PL, Schuling J. Raamplan huisartsopleiding. Utrecht: Raad voor de Huisartsopleidingen; 2001. www.svuh.nl, onder: 'Publicaties'.

5. Schlusmans K, Slotman R, Nagtegaal C, Kinkhorst G. Competentiegerichte leeromgevingen. Utrecht: Lemma; 2000. p. 42-4, 225-37.

6. Haan M de, Boendermaker PM, Heij I. Het medisch ambacht. Maarssen; Elsevier; 2002. p. 2830, 80-6.

7. Miller GE. The assessment of clinical skills/ competence/performance. Acad Med 1990:65(9 Suppl): 63-7.

8. Geijer RMM, Thiadens HA, Smeele IJM, Sachs APE, Bottema BJAM, Hensbergen W van, et al. NHG-standaard COPD en astma bij volwassenen: diagnostiek. Huisarts Wet 2001;44:107-17.

9. Janson C, Chinn S, Jarvis D, Burney P. Physician diagnosed asthma and drug utilisation in the European Community Respiratory Health Survey. Eur Respir J 1997;10:1795-1802.

10. Rabe KF, Vermeire PA, Soriano JB, Maier WC. Clinical management of asthma in 1999: the Asthma Insights and Reality in Europe (AIRE) study. Eur Respir J 2000;5:802-7.

11. Geijer RMM, Hensbergen W van, Bottema BJAM, Schayck CP van, Sachs APE, Smeele IJM, et al.
NHG-standaard astma bij volwassenen: behandeling. Huisarts Wet 2001;44:153-64.

12. Crim C. Clinical practice guidelines vs actual clinical practice. Chest 2000;118:62-4.

13. Smeele IJ, Grol RP, Schayck CP van, Bosch WJ van den, Hoogen HJ van den, Muris JW. Can small group education and peer review improve care for patients with asthma/ chronic obstructive pulmonary disease? Qual Health Care 1999; 8:92-8.

14. Geraerdts M, Selbmann HK, Meisner C. Effects of a regional intervention to promote asthma guidelines implementation. Gesundheitswesen 2002; 64:235-41.

15. Blackstein-Hirsch P, Anderson G, Cicutto L,

McIvor A, Norton P. Implementing continuing education strategies for family physicians to enhance asthma patients' quality of life. J Asthma 2000;37:247-57.

16. Premaratne UN, Sterne JAC, Marks GB, Webb JR, Azima H, Burney PGJ. Clustered randomised trial of an intervention to improve the management of asthma: Greenwich asthma study. BMJ 1999;318: 1251-5.

De auteurs:

Drs. B.J. van Duin is huisarts en staflid Huisartsopleiding, Vrije Universiteit Medisch Centrum Amsterdam. Mw. dr. A.E. Hesselink is onderzoeker, destijds werkzaam bij het EMGO-Instituut, Vrije Universiteit Medisch Centrum Amsterdam.

Correspondentieadres:

Drs. B.J. van Duin, Beukenrode 274, 2215 JR Voorhout, bj.van.duin@wanadoo.nl.

\section{Summary}

Introduction: In order to improve GP trainees' competencies in asthma management, a general practice based elective module was developed at the Free University Medical Center (VUmc), Amsterdam, the Netherlands. The trainees are attached to a general practice and during the module they were responsible for the management of patients in this practice whose asthma was inadequately controlled. The GP trainees also attend educational sessions, running in parallel with the patient consultations as regards both content and timing.

Method: In 2001 and 2002, 16 GP trainees took care of 72 patients, 38 of whom completed all (> 3) consultation sessions with the trainee. The Dutch general practice guidelines on asthma provided the structure for the consultations and the findings were recorded.

Results: The feasibility of the programme was good. There were no differences in gender, age and diagnosis between the patients who did and the patients who did not complete the programme. Comparison between the first and the last consultations showed a significant improvement in both symptoms and lung function in those patients who attended all consultation sessions.

Discussion and conclusions: A practice-based educational module on chronic disease appeared not only to help GP trainees apply guidelines in a systematic way, but also to improve the quality of patient care. This educational approach, in which training and improvement of quality of care go side by side may also be applicable in other educational programmes in health care which combine learning and working in practice. (Van Duin BJ, Hesselink AE. A competency-based elective module on asthma management for GP trainees: an educational approach to quality of care and its effects on the clinical condition of the supervised patients. Dutch Journal of Medical Education 2004;23(6):281-290.) 